\title{
A low noise, microprocessor-controlled, internally digitizing rotating-vane electric field mill for airborne platforms
}

\author{
M.G. Bateman ${ }^{1}$, M.F. Stewart ${ }^{2}$, R.J. Blakeslee ${ }^{3}$, S.J. Podgorny ${ }^{2}$, \\ H.J. Christian ${ }^{3}$, D.M. Mach ${ }^{2}$, J.C. Bailey ${ }^{4}$ and D. Daskar ${ }^{5}$ \\ ${ }^{1}$ Universities Space Research Association, Huntsville, AL \\ ${ }^{2}$ University of Alabama in Huntsville \\ ${ }^{3}$ NASA/Marshall Spaceflight Center, Huntsville, AL \\ ${ }^{4}$ Raytheon/ITSS, Huntsville, AL \\ ${ }^{5}$ Engineering Research Consulting, Huntsville, AL
}

June 5, 2006

submitted to the Journal of Atmospheric and Oceanic Technology

\begin{abstract}
This paper reports on a new generation of aircraft-based rotating-vane style electric field mills designed and built at NASA's Marshall Spaceflight Center. The mills have individual microprocessors that digitize the electric field signal at the mill and respond to commands from the data system computer. The mills are very sensitive ( $1 \mathrm{~V} / \mathrm{m}$ per bit), have a wide dynamic range (115 dB), and are very low noise ( $\pm 1 \mathrm{LSB})$. Mounted on an aircraft, these mills can measure fields from $\pm 1 \mathrm{~V} / \mathrm{m}$ to $\pm 500 \mathrm{kV} / \mathrm{m}$. Once-per-second commanding from the data collection computer to each mill allows for precise timing and synchronization. The mills can also be commanded to execute a self-calibration in flight, which is done periodically to monitor the status and health of each mill.
\end{abstract}

\section{Introduction}

A rotating-vane style electric field mill is an instrument designed to measure the Earth's quasi-static atmospheric electric field. This configuration employs an electric field modulator consisting of stationary sensing electrodes and a 
rotating shield electrode. The mill alternately shields and exposes the sensing plates to the external electric field. The time-varying charge induced by the ambient electric field on the sensing plates is converted to a voltage by a charge amplifier.

The earliest known implementation of a rotating vane field mill was detailed by Harnwell and Van Voorhis (1933). The theory of operation of an electric field mill is discussed by Mapleson and Whitlock (1955) and also Israël (1973). A history of various types of electric field machines is given by Chalmers (1967). A detailed description of a contemporary design is found in Winn (1993). A method of absolute and form-factor calibration is given by MacGorman and Rust (1998). The method of aircraft form-factor calibration that we use has been detailed in several publications (Mach and Koshak 2003; Koshak 2006; Koshak et al. 2006). This paper describes the field mills designed and built at NASA's Marshall Spaceflight Center, intended for use on aircraft. In addition to describing key design features of these mills, we will address the approach taken to solve problems specific to making measurements from an airborne platform.

\section{Instrument Design}

\section{2a. Requirements}

The two primary requirements for an airborne electric field mill are (1) the capability of measuring both the foul and fair weather fields with adequate precision, and (2) the ability to perform the measurement in the presence of adverse environmental conditions. Typical thunderstorm electric fields vary from a few kilovolts per meter $(\mathrm{kV} / \mathrm{m})$ to a few hundred $\mathrm{kV} / \mathrm{m}$. However, the ambient electric field can be substantially smaller than the field due to the time-varying charge on the aircraft, so a high degree of precision must be maintained over a large dynamic range. Charge on the aircraft can make the measured field values very large, and calculating the ambient field often involves subtracting two very large, nearly equal numbers to arrive at a much smaller number, making high precision most important.

The requirement to measure fair weather electric fields arises from the need to measure the signals associated with aircraft calibration maneuvers performed under fair weather conditions. The enhancement effects of the complex aircraft geometry are most readily accounted for by performing maneuvers that change the aircraft orientation about one axis at a time, such as a roll or pitch, while the aircraft is immersed in the homogeneous vertical fair weather field. At an altitude of a few kilometers, the magnitude of the fair weather field is $20-30 \mathrm{~V} / \mathrm{m}$. Thus we need to be able to resolve fields on the order of $1 \mathrm{~V} / \mathrm{m}$. This implies the need for an overall dynamic range of $>100 \mathrm{~dB}$.

The environment to which the mills will be exposed while flying places severe demands on the instrument design. Ambient temperatures can vary from $+50^{\circ} \mathrm{C}$ on the runway to $-60^{\circ} \mathrm{C}$ at altitude. The mills are subjected to atmospheric pressures ranging from sea level to $55 \mathrm{hPa}$ at $20 \mathrm{~km}$ altitude. Drenching rains can be encountered in flight 
and on the runway, and freezing rain and ice can be encountered during flight. The aircraft can impose sustained mechanical and acoustic vibration in flight and shock upon landing.

Determination of the three components of the vector electric field and the time-varying electrical charge on the aircraft requires that at least four mills be mounted on the aircraft. In practice, primarily because of symmetry considerations and to provide redundancy of measurement, five to eight mills are deployed about an aircraft. Typically the combined weight of the electric field instrumentation is not a significant contributor to the total payload weight, except for light-weight aircraft such as Unmanned Aerial Vehicles (UAVs). The physical size of a mill is significant in as much as (1) apertures are required in the fuselage to allow the modulator to be exposed to the atmosphere and (2) desirable mounting locations may be cramped or result in a mill protruding into the cabin.

\section{2b. Electric Field Modulator Design}

A rotating vane electric field mill detects a static external electric field by means of a mechanical modulator that produces a time-varying induced electrical charge signal. The required modulator components are (1) sense electrodes, (2) a stable platform or base on which to mount the sense electrodes, (3) insulators to electrically isolate the sense electrodes from the base, (4) a rotating shield electrode (rotor), and (5) a motor to drive the shield electrode. To reduce the ingress of precipitation or other contaminants, the NASA/MSFC mill also employs (6) a grounded guard ring that surrounds these components. Variants of this configuration are possible, e.g., a stationary shield electrode with a moving sense electrode.

An external electric field is detected as the rotor electrode alternately covers and uncovers the sense electrodes. An electric charge is induced in the sense electrodes when they are uncovered, resulting in an oscillating charge signal that varies in amplitude with the external electric field. This charge signal has (1) an amplitude proportional to the vector component of the electric field normal to the plane of the modulator, (2) a period related to the rotational velocity of the rotor and (3) a phase related to the position of the rotor with respect to the sense electrodes.

Figures 1 and 2 depict the physical configuration of the modulator. The spacings between the sense electrodes, the rotor, and the guard ring are sized to avoid bridging by precipitation or other contaminants that can result in measurement error due to leakage currents. Drain holes in the guard ring are used when the location and orientation of a mill is such that precipitation can accumulate in the modulator.

All the components of the modulator except the insulators and the motor are fabricated from type 316 stainless steel with surfaces that are highly polished (\#8 finish) and passivated to reduce the effects of corrosion. The insulators are fabricated from Kel-FTM (polychlorotrifluoroethylene or PCTFE) which is used for its very low hygroscopic and nonpiezoelectric properties. Degradation of the insulation resistance in the presence of high humidity or other conductive contaminants can produce measurement error. Noise currents induced by aircraft vibration can mask low level field 
signals.

A brushless DC motor is used to drive the rotor to avoid the high level of wideband noise associated with the arcing of brushes in a conventional DC motor. As depicted in Figure 2, the motor is enclosed in an electrostatic shield to reduce electrostatic coupling of high level motor commutation voltages to sensitive circuits. This shielding also intercepts RF energy from radio communications or aircraft radar that may be coupled into the motor-rotor assembly.

Not shown in Figure 2 is the cover that seals the rear of the mill to avoid providing a depressurizing leakage path for the cases where a mill is installed in a cabin area. A picture of one of our mills is shown in Figure 3.

\section{2c. Signal Processing Circuits}

The block diagram (Fig. 4) illustrates the signal flow through the detection and signal processing electronics. The charge signal induced by the modulator is detected and converted to a voltage signal by charge amplifiers (see Fig. 5). As described in Tobey et al. (1971), the salient features of a charge amplifier are that the gain is inversely proportional to the feedback capacitance, and a high pass response is formed by the parallel resistance required to bias the inverting input of the operational amplifier. The charge amplifier inputs are connected to the sensing electrodes through feedthrough capacitors to filter $R F$ energy that may be produced by aircraft communication equipment or radar. These inputs are also protected from coupled transient energy by shunt clamping diodes, such as TransZorbs ${ }^{\circledR}$. More detail on designing charge amps as used in field mills can be found in MacGorman and Rust (1998).

Additional voltage gain is employed following the charge amplifiers to set up two channels in which the charge amplifier signals are rectified and filtered to extract the magnitude and polarity of the electric field. The polarity is determined by a timing signal derived from a slotted optical switch that indicates a specific angular position of the motor shaft. Flat plate calibration confirms that the resolution of the field mills is $1.94 \mathrm{~V} / \mathrm{m}$ per bit (sensitive channel). The A/D converters are 16-bit bipolar, which gives a maximum field of $63.6 \mathrm{kV} / \mathrm{m}$ (sensitive) and $1.15 \mathrm{MV} / \mathrm{m}$ (insensitive). When the mills are mounted on an aircraft, the electric field is enhanced by about a factor of 2 (cylinder enhancement). This means that the detectable field in fight ranges from about $1 \mathrm{~V} / \mathrm{m}$ to about $575 \mathrm{kV} / \mathrm{m}$, which is considerably greater than fields typically found inside thunderstorms.

The signal spans of the two channels overlap, maximizing resolution across the overall dynamic range. Careful attention to the noise budget throughout the signal processing chain resulted in mills with an internal noise of about \pm 1 LSB on the sensitive channel. This design results in a usable dynamic range of $115 \mathrm{~dB}$. A summary of the performance specifications is given in Table 1. 


\section{2d. Microprocessor Controller and Data System}

The use of an embedded microprocessor (Motorola M68HC11E) provides several benefits. One is that the digitized electric field data can be organized into packets, with mill configuration and status information, for digital serial transmission. Having a record of mill operating parameters such as motor speed, instrument temperature, motor current and temperature, and programmable configuration settings can be very helpful in diagnosing problems that may appear only during flight. The serial number of each mill is also included in the data packet so that calibration data specific to each mill can be properly applied.

The data packet containing $1 \mathrm{~s}$ of data consists of: 12 bytes of header data, 50 samples ( 100 bytes) of low sensitivity electric field, 50 samples of high sensitivity electric field, and 2 bytes of checksum for a total of 214 bytes. This packet size allows us to send the data over a 2400 baud serial link. The 16-bit checksum (CRC-CCITT) is computed over each packet and included with the transmission to ensure that corrupted data are not used.

Another benefit of using a microprocessor is to enable a mill to respond to commands from the data system during flight. When the data system sends a "normal" command to a mill, two things happen simultaneously: (1) the mill begins collecting Is of data, and (2) the mill sends out data collected during the previous second. This handshaking between the data system and the mills occurs on the second, thereby synchronizing the data collection for each mill. The periodicity of these commands is regulated by a GPS referenced timing source. As a result, the electric field is sampled with better than $1 \mathrm{~ms}$ UTC knowledge and uniformity.

The mills also respond to commands that impose controlled simulated bipolar test electric fields on the modulator. The data system broadcasts these commands periodically (typically every $10 \mathrm{~min}$ ) to all the mills, which should result in a repeatable and well-defined superposition of the test electric fields on the ambient fields in the records. This allows in-flight verification of mill operation and electric field sensitivity. A properly functioning mill will exhibit periodic, consistent bipolar field excursions that can be readily removed during post processing.

The data collection computer communicates with the field mills via RS-232 serial protocol, using one port per mill. We have used a standard desktop PC in a rack-mountable enclosure, located inside the aircraft cabin. We have also used PC-104 and VMEbus format embedded computers, each enclosed in a sealed environmental box and mounted in less pressure- and temperature-controlled locations in an ER-2 aircraft and Altus-II UAV.

\section{2e. Grounding and Interference Control}

In order for a mill to properly sense the electric field external to an aircraft, the modulator must be exposed to the external field and bonded to the fuselage. However, the fuselage is also used as the electrical return for aircraft power systems. This means that large noisy currents can flow from forward locations to aft locations where the power generation equipment is usually located. To avoid providing alternate paths for these currents through internal mill 
circuitry and interconnect wiring, all power and command/data interconnections to the mills are electrically isolated. This is achieved by employing isolated DC/DC converters to supply power to mill circuitry and optical isolation on the asynchronous communications lines. Additional optical isolation is used internally to separate noisy circuitry from sensitive analog circuits.

A significant source of noise during flight is the interference due to the charge on the aircraft. During flight the impact of precipitation on the aircraft leads to a time-varying accumulation of surface charge. The contamination of the external electric field by the electrical charge residing on dielectric surfaces near a mill can be substantial and exhibit very long relaxation times. Two approaches have been used to reduce this effect. For the NASA-sponsored Airborne Field Mill (ABFM) program that utilized a NASA/Langley Lear Jet in the 1980s, paint on the fuselage around a mill was removed down to the bare metal. This is effective but exposes the aircraft skin to corrosion. For the University of North Dakota Cessna Citation, electrically conductive paint was applied around each mill, and this conducting surface was well connected to the airframe. Control of the surface charge within a radius at about $0.5 \mathrm{~m}$ is usually adequate. This approach has also been used on some locations on the NASA ER-2 and all locations on the Altus-II UAV.

Another situation arises when a fiberglass fairing must be used to mount a mill on an aircraft. This has been done for some locations on the NASA ER-2s. In this case, metalized tape was applied to the interior of the fairing and bonded to the airframe to establish an electrical shape for the mounting. Although the outer surface of the fairing was still a dielectric, the ER-2 rarely encounters clouds at its operating altitude $(15-20 \mathrm{~km})$. Also at this altitude, the atmosphere is considerably more conductive, and accumulated charge bleeds off the aircraft very quickly.

While these techniques can reduce the effects of local surface charging, the interference due to time-varying overall net aircraft charge is not mitigated. The field due to net aircraft charge is dealt with in the aircraft calibration process.

\section{Calibration and Testing}

\section{3a. Mill Calibration}

Each mill is calibrated by exposing it to a known electric field in the lab. This field is created using two parallel conducting plates (we use a setup with plates $1 \mathrm{~m}^{2}$ area and $14 \mathrm{~cm}$ separation; see Fig. 6) across which a known high voltage is applied. The sensor end of a field mill is placed in a hole in one of the plates, such that the front end of the mill is flush with the plate. This keeps a known, uniform field between the plates - since the mill is flush-mounted, it does not distort the field. The response of each mill to 10 settings of electric field for both polarities is used to evaluate its sensitivity, DC offset, dynamic range, and linearity. These calibration values are then used to determine the regression-line model for each mill.

Each mill is assigned a serial number when manufactured, which is burned into the mill's firmware and is included 
in the data stream. This fixed serial number allows us to apply the calibration coefficients unique to each mill, even if mills get moved around to different aircraft locations during a field program. We also use the serial number to apply appropriate calibration coefficients in analysis/display software.

\section{3b. Geometric Calibration}

When an instrumented aircraft is placed in an electric field, its geometric shape will distort the external field. It is the components of these distorted fields, and not the true external electric field that are measured by the mills on the aircraft. Analytical solutions exist for simple geometric shapes such as cylinders and spheres, however, an aircraft is inherently not a simple shape. Its effect on the external electric field is complicated, and must be determined empirically. The enhancement factors will be unique for each component of the electric field at each mill location on the aircraft. Working through the geometric calibration gives us the enhancement factors for each mill location and ultimately allows us to calculate what was the ambient electric field in the absence of the aircraft.

Winn (1993) describes techniques of using linear combinations of mills to deduce the vector components of the electric field $\left(E_{x}, E_{y}, E_{z}\right)$. Our approach is similar, but involves calculating linear combinations of mill outputs during a calibration flight. The aircraft is flown in a region where the electric field is uniform - for example, during fair weather, in a cloudless sky. This gives a uniform, vertical, fair-weather field, which is known to first order as a function of altitude (Gish 1944). The pilot performs maneuvers so that the uniform vertical field is rotated into the other aircraft frame field components. The reference coordinate system used is: $x$ axis along the fuselage (roll axis), positive in the direction of flight; $y$ axis along the wings (pitch axis), positive out the left wing; $z$ axis perpendicular to the wings and fuselage (yaw axis), positive up during level flight. For example, pitching up or down (rotation about the $y$ axis) translates the vertical component of the electric field (where $E_{y}$ and $E_{x}$ are 0 ) into the aircraft $x$ and $z$ frame. From simple geometric principles, the $E_{x}, E_{y}$, and $E_{z}$ components during a pitch maneuver of angle $\phi$ when the external field is vertical and equal to $E_{v}$ can be represented by the following formula:

$$
\begin{aligned}
& E_{x}=E_{v} \sin (\phi) \\
& E_{y}=0 \\
& E_{z}=E_{v} \cos (\phi)
\end{aligned}
$$


Similarly, a roll maneuver (rotation about the $x$ axis) of angle $\theta$ will create the following fields in the aircraft frame of reference:

$$
\begin{aligned}
& E_{x}=0 \\
& E_{y}=E_{v} \sin (\theta) \\
& E_{z}=E_{v} \cos (\theta)
\end{aligned}
$$

We then map the mill outputs during the maneuvers (using matrix manipulations) to produce a matrix which represents the external electric field as a function of the mill outputs and the aircraft orientation. The details of this calibration procedure can be found in Mach and Koshak (2003).

The roll and pitch maneuvers give us a relative calibration for a particular aircraft installation. The final step is to get an absolute calibration. To do this, the aircraft makes a low pass near a calibrated, ground-based field mill. The absolute calibration factor is then derived by comparing the field measurement of the ground-based field mill and the aircraft mills.

\section{Sample Data}

We have used these field mills in numerous field campaigns to collect a large volume of high quality data. We present here some example electric field data taken from several aircraft platforms and different weather scenarios. First is an overflight of a Florida airmass thunderstorm by a NASA ER-2 high-altitude aircraft. Next is an overflight of the eyewall of Hurricane Bonnie, again with the ER-2. Last is an example set of pitch and roll maneuvers used for calibration, performed by an Altus-II UAV aircraft. These examples demonstrate the low noise, high dynamic range and resolution of our field mills.

\section{4a. Thunderstorm North of Tampa, FL}

Shown in Figs. 7 and 8 are time-series plots of electric field data. Figure 7 shows the eight individual mill outputs, while Figure 8 shows the vector components calculated from them. The three spatial components are $E_{x}, E_{y}$, and $E_{z}$ (in the aircraft frame of reference); the fourth component is the field due to charge on the aircraft, $E_{q}$. In this case the mills were flown on a NASA ER-2. These data are from an overflight $(\sim 21 \mathrm{~km}$ altitude) of a large thunderstorm north of Tampa, FL on 05 Sep 1998. According to the ER-2 Doppler radar (EDOP), the cloud tops were around $15 \mathrm{~km}$ and the reflectivity in the storm exceeded $60 \mathrm{dBZ}$. Note that the fields were mostly vertical $\left(E_{z}\right)$ and centered on the storm. The raw fields at the mills (Fig. 7) are dominated by the charge on the aircraft, as seen by their resemblance to 
Fig. 8, plot $E_{q}$. A calibration matrix is determined for each aircraft installation (e.g., Mach and Koshak 2003) and is used to make the linear combinations of mill outputs needed to calculate the field components (Fig. 8). For example, charge on the aircraft ( $E_{q}$ in Fig. 8) can be roughly calculated by adding the first two mill outputs shown in Fig. 7 $(Q U+Q L)$. Then, since these mills essentially point vertical (with one up and one down) in level flight, the vertical field component $\left(E_{z}\right)$ can be roughly calculated by subtracting the two mill outputs: QU - QL. The actual calibration matrix is more complicated.

\section{4b. Over Hurricane Bonnie Eyewall}

Shown in Fig. 9 are plots of electric field data for an ER-2 overpass of Hurricane Bonnie on 26 Aug 1998 (e.g., Hood et al. 2006). The upper half of the page is a 3-panel diagram, with all showing $\mathbf{E}$ vectors superimposed on the aircraft track. The top panel is an $x-z$ display showing aircraft track and electric field vectors $\left(E_{x}\right.$ and $\left.E_{z}\right)$ in that plane. The panel on the right is a $y-z$ display, again showing aircraft track and electric field vectors ( $E_{y}$ and $E_{z}$ ) in that plane. The large, center panel is an $x-y$ display showing the aircraft track and electric field vectors ( $E_{x}$ and $E_{y}$ ) in that plane. There is a scale in each panel for the vector length. Note that the $E_{z}$ field is typically an order of magnitude larger than the horizontal components, so the vectors in the $x-z$ and $y-z$ panels are scaled differently from those in the $x-y$ panel. The vector "barbs" shown are oriented so that the tail of the arrow is attached to the flight track; the electric field sign convention is that the vectors point away from positive charge.

The eye of the hurricane is at the center of the plot, where the 5 legs of flight track cross multiple times. During the first leg, the plane flies eastward, crosses the eye, and turns NNW just after 14:30. The second leg is short, ending with the plane turning SW at about 14:45. Leg 3 takes the plane across the eye again at 15:00, and then it passes near a convective cell in one of the rainbands, as shown by the $\mathbf{E}$ vectors. The plane then turns eastward to begin leg 4 at about 15:15. Again, the $\mathbf{E}$ vectors show electrified cloud to the north. Leg 5 begins with the plane turning NW just after 15:30 and it makes another pass across the eye. Just before reaching the eye, at about 15:40, the plane crosses over a small patch of intense convection just outside the eyewall. The flight track shown ends at 16:00 UTC. The bottom half of the page is a time-series plot of the vector components, as before.

\section{4c. Pitches and Rolls maneuvers in fair weather field}

Shown in Fig. 10 are the calculated vector components of $\mathbf{E}$ during fair weather conditions. These data were taken using an Altus-II UAV that carried 6 field mills. Shown is a calibration dataset when the aircraft was executing roll and pitch maneuvers in a uniform fair weather field. Using the procedures described in section $3 b$, we can use the mill output data along with the roll and pitch angles and the calculated fair weather field at flight altitude (Gish 1944) to determine the aircraft calibration matrix, which in turn is used to create the plots shown in Fig. 10. 
Points to note about the data plot: (1) Although the pitch angles are less than $10^{\circ}$ and the external field less than $20 \mathrm{~V} / \mathrm{m}$, the very low noise characteristics of the mills and aircraft allow us to clearly detect the pitch maneuvers in the field measurements (see "bumps" around 16:14 UTC and 16:17 UTC in the $E_{x}$ plot), (2) The roll maneuvers can be clearly seen in the $E_{y}$ plot (around 16:13 and 16:15 UTC), (3) The roll maneuvers can also be seen in the $E_{z}$ plot, as rolling the aircraft reduces the $E_{z}$ component of the field by the cosine of the roll angle (see Eqs. 1 and 2), (4) The change in aircraft charge, $E_{q}$, just prior to $16: 17$ was likely caused by changing the engine RPM in preparation for the second set of pitch maneuvers, (5) We are able to resolve to $1 \mathrm{~V} / \mathrm{m}$, and that the signal is significantly larger than the noise, and (6) The aircraft was flying at $3.2 \mathrm{~km}$; the calculated fair weather field at that altitude, to first order is $-18 \mathrm{~V} / \mathrm{m}$. Our measured $E_{z}$ field shows good agreement with the calculated value.

\section{Concluding Remarks}

Our goal was to design a new generation of aircraft-based electric field mills that were sensitive, low-noise, rugged and lightweight. We have produced field mills that have: (a) high sensitivity (1 V/m per bit), (b) wide dynamic range $(115 \mathrm{~dB})$, and $(\mathrm{c})$ very low noise $(\sim \pm 1 \mathrm{LSB})$. These mills have also proven themselves to be rugged enough to perform on multiple aircraft through many field campaigns ( 8 to date). These mills have performed well (at and beyond spec) due to careful engineering of many details throughout the signal path of the instrument. Their design and construction have benefited from "lessons learned" with previous generations of aircraft-based field mills.

Acknowledgement We thank Alys Blair for her valuable contributions in the mechanical design and prototype testing of the field mills. 


\section{References}

Chalmers, J. A., 1967: Atmospheric Electricity. Pergamon Press, London, 515 pp.

Gish, O. H., 1944: Evaluation and interpretation of the columnar resistance of the atmosphere. Terr. Magn. Atmos. Elec., 49, 159-168.

Harnwell, G. P. and S. N. Van Voorhis, 1933: An electrostatic generating voltmeter. Rev. Sci. Inst., 4, $540-542$.

Hood, R. E., R. J. Blakeslee, M. Goodman, D. J. Cecil, D. M. Mach, F. J. LaFontaine, G. M. Heymsfield, F. D. M. Jr., and E. J. Zipser, 2006: Classification of tropical oceanic precipitation using high-altitude aircraft microwave and electric field measurements. J. Atmos. Sci., 63, 218-233, doi:10.1175/JAS3606.1.

Israël, H., 1973: Atmospheric Electricity, Vol. 2, Fields, Charges, Currents. Israel Program for Scientific Translation, Jerusalem, $478 \mathrm{pp}$.

Koshak, W. J., 2006: Retrieving storm electric fields from aircraft field mill data. Part I: Theory. J. Atmos. Oceanic Tech., accepted.

Koshak, W. J., D. M. Mach, H. J. Christian, M. F. Stewart, and M. Bateman, 2006: Retrieving storm electric fields from aircraft field mill data. Part II: Applications. J. Atmos. Oceanic Tech., accepted.

MacGorman, D. R. and W. D. Rust, 1998: The Electrical Nature of Thunderstorms. Oxford University Press, New York, $422 \mathrm{pp}$.

Mach, D. and W. Koshak, 2003: General matrix inversion technique for the calibration of electric field sensor arrays on aircraft platforms. Proc. ICAE, Intl. Conf. Atmos. Elec., Versaille, France, 207-210.

Mapleson, W. W. and W. S. Whitlock, 1955: Apparatus for the accurate and continuous measurement of the earth's electric field. J. Atmos. Terr. Phys., 7, 61-72.

Tobey, G. E., J. G. Graeme, and L. P. Huelsman, 1971: Operational Amplifiers: Design and Applications, McGrawHill, New York, NY. 233-235.

Winn, W. P., 1993: Aircraft measurement of electric field: Self-calibration. J. Geophys. Res., 98, 7351-7365, doi:10.1029/93J00165.

TransZorb $^{\circledR}$ is a registered trademark of Vishay Semiconductors, Malvern, PA. 
Electric field detection (flush-mounted on flat plate):

\begin{tabular}{|c|c|}
\hline \multicolumn{2}{|l|}{ Dynamic range } \\
\hline Sensitive channel & $\pm 1.9 \mathrm{~V} / \mathrm{m}$ to $64 \mathrm{kV} / \mathrm{m}$ \\
\hline Insensitive channel & $\pm 34 \mathrm{~V} / \mathrm{m}$ to $1.1 \mathrm{MV} / \mathrm{m}$ \\
\hline \multicolumn{2}{|l|}{ Noise } \\
\hline Zero field error & $\leq \pm 25 \mathrm{~V} / \mathrm{m}$ \\
\hline Field uncertainty & $\leq \pm 1.9 \mathrm{~V} / \mathrm{m}$ \\
\hline Sensitivity & $1.9 \mathrm{~V} / \mathrm{m}$ per LSB \\
\hline Accuracy & $\pm 2.5 \%$ \\
\hline Bandwidth $(-3 \mathrm{~dB})$ & $10 \mathrm{~Hz}$ \\
\hline Sampling rate & 50 samples/s \\
\hline
\end{tabular}

Physical:

\begin{tabular}{|c|c|}
\hline Mass & $21 \mathrm{~kg}$ \\
\hline \multirow{3}{*}{ Power } & $+28 \mathrm{VDC} \pm 5 \%$ \\
& $250 \mathrm{~mA}$ (heater off) \\
& $500 \mathrm{~mA}$ (heater on) \\
\hline
\end{tabular}

Operating environment:

\begin{tabular}{|l|l|}
\hline Temperature & -55 to $+50^{\circ} \mathrm{C}$ \\
\hline Altitude & Sea level to $21 \mathrm{~km}$ \\
\hline Humidity & to $100 \%$ \\
\hline
\end{tabular}

Table 1: Performance specifications for the NASA/MSFC electric field mills as configured in a flush mount (flat plate). Zero field error is the value of electric field reported when the external field is zero. Field uncertainty is the instrument noise $(\leq \pm 1 \mathrm{LSB})$ expressed in physical units using a conversion constant derived from flat-plate calibration testing. To get the "as used" specs (mounted on an aircraft), roughly divide the field values by 2 . 


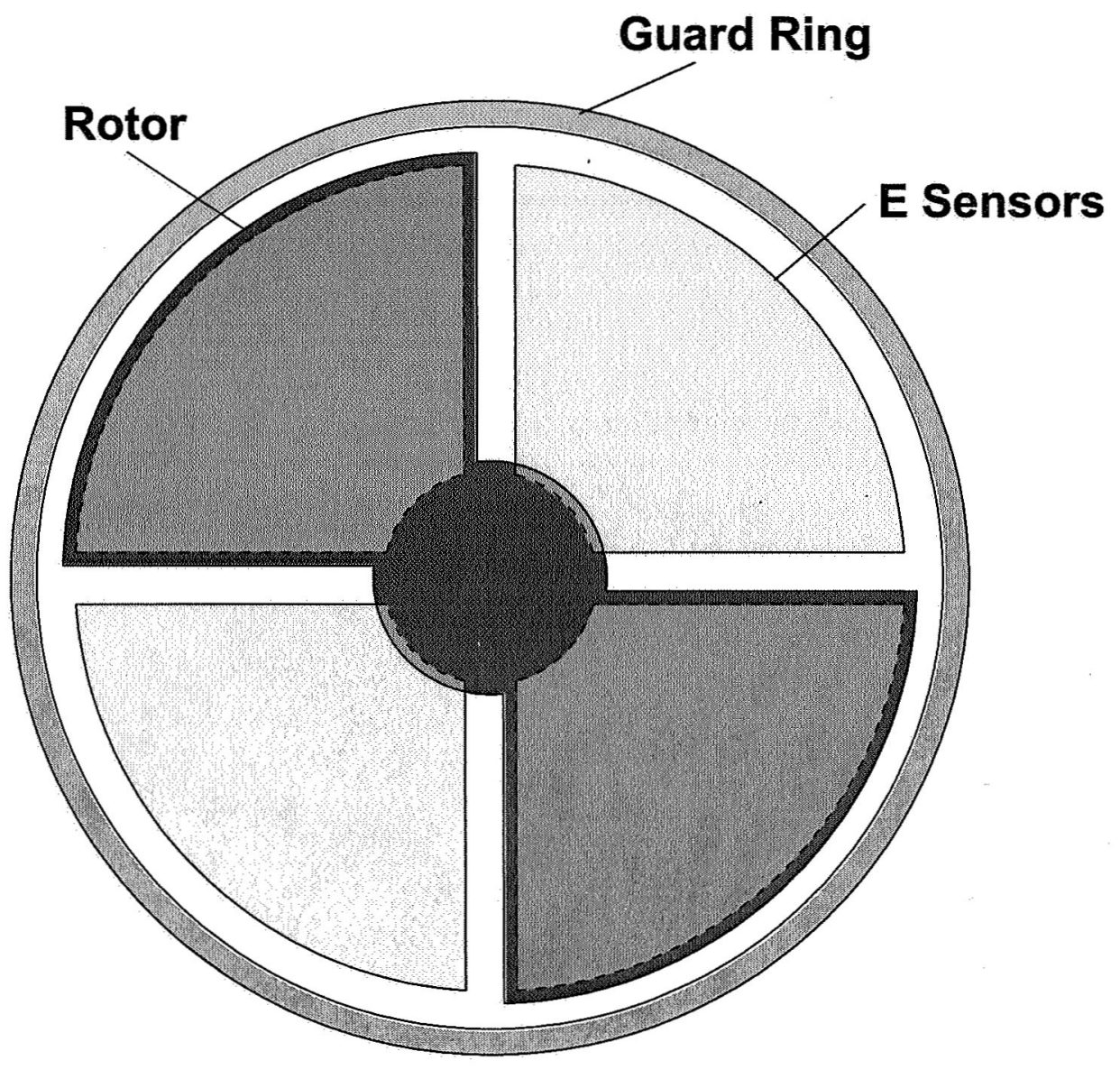

Figure 1: Shown is a top view of the E-field sensor. Note that the grounded rotor is "bowtie" shaped so that it covers one pair of sensors, and is slightly wider in angle and slightly larger in diameter than the $\mathrm{E}$ sensors (thus ensuring coverage). This geometry was specified so that the two sensors under the rotor are indeed completely covered. 


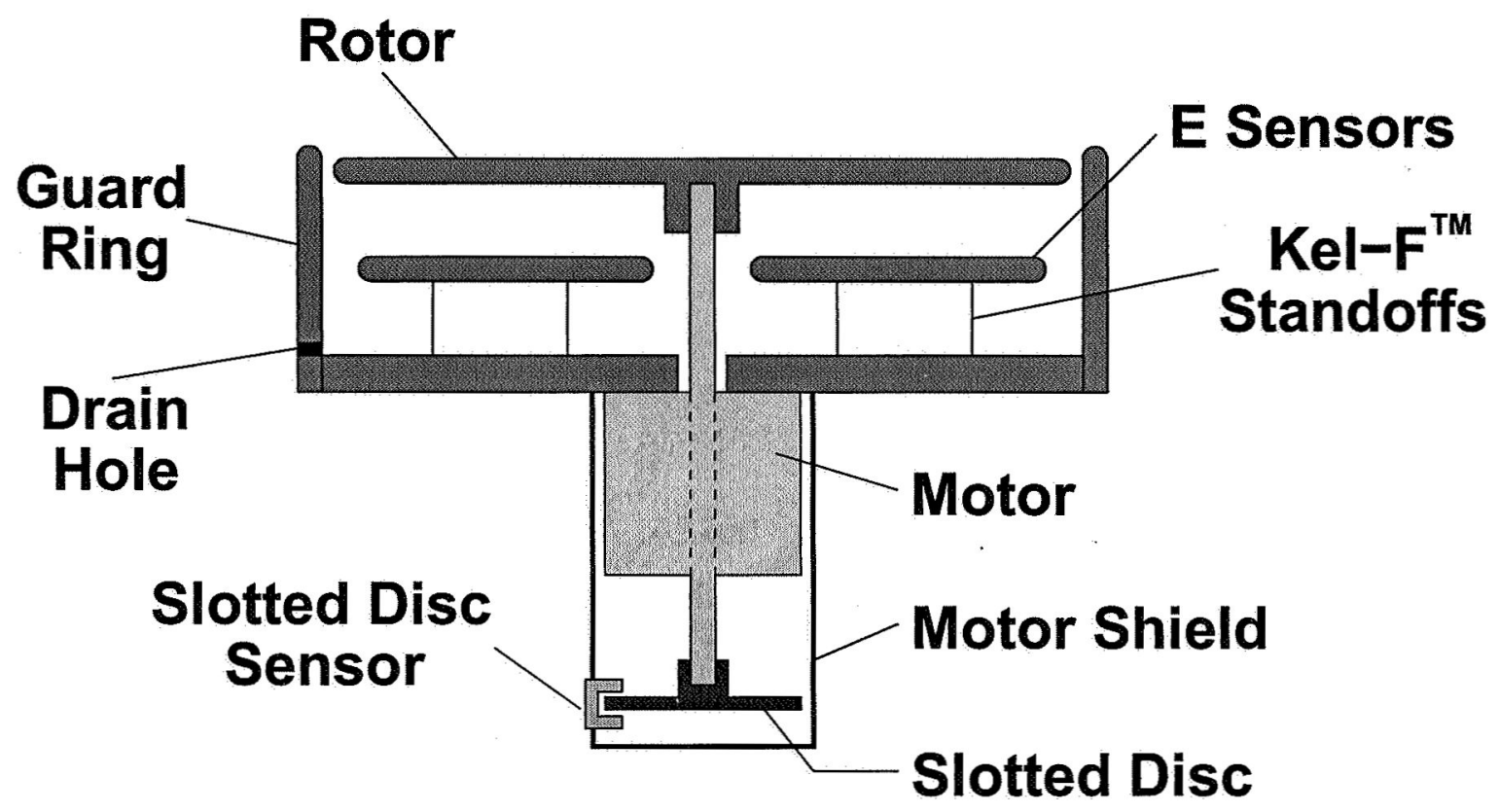

Figure 2: Shown is a side view of the E-field sensor. Note that the rotor and the slotted disc are attached to opposite ends of the motor's output shaft, which is all the same piece of metal. The slotted disc provides, via the disc sensor, phasing information for the rotor. The E sensors are supported by standoffs made from Kel-F ${ }^{\mathrm{TM}}$. The grounded guard ring shields the sensors from contamination and interference that would come from the sides (horizontal as shown). The rotor, sensors, and guard ring are made from highly polished 316 stainless steel. The E sensors, motor shaft, and guard ring are spaced to minimize bridging (shorting) by precipitation. There are 2 oval-shaped drain holes cut in the guard ring, about $1 \mathrm{~cm} \times 0.5 \mathrm{~cm}$, which allow the sensor assembly to drain any collected water. The motor is a brushless DC motor. This type of motor creates less electrical noise than a conventional motor with brushes, and lasts longer. Since the spinning rotor is exposed to RF energy (communication radio for the airplane, radar, etc.) and the motor is connected to the rotor, we place a shield can around the motor to prevent RF from being re-radiated into the field mill analog circuitry. 


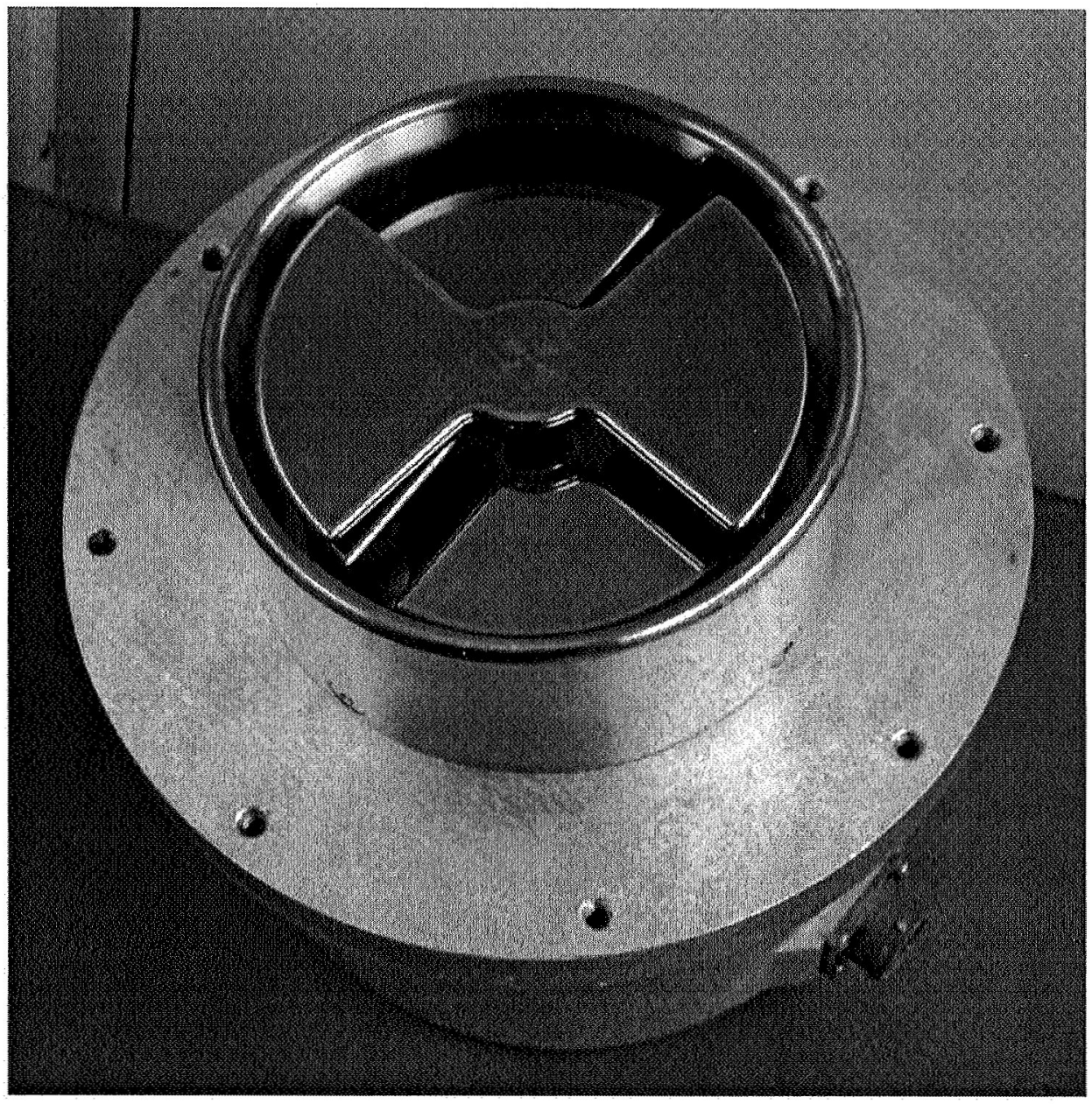

Figure 3: Shown is a picture of a field mill. 


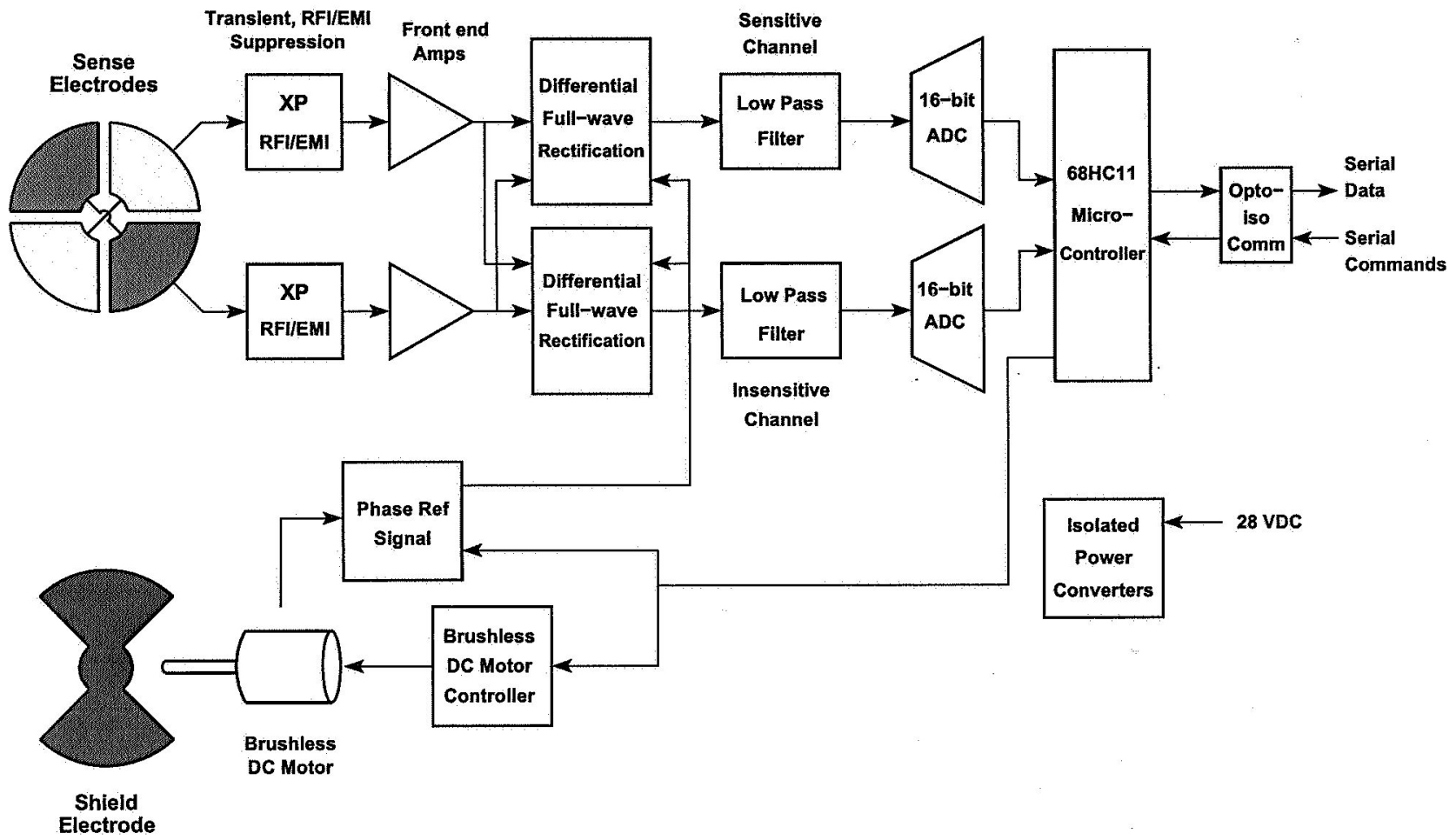

Figure 4: Shown is a block diagram of the field mill circuitry. 


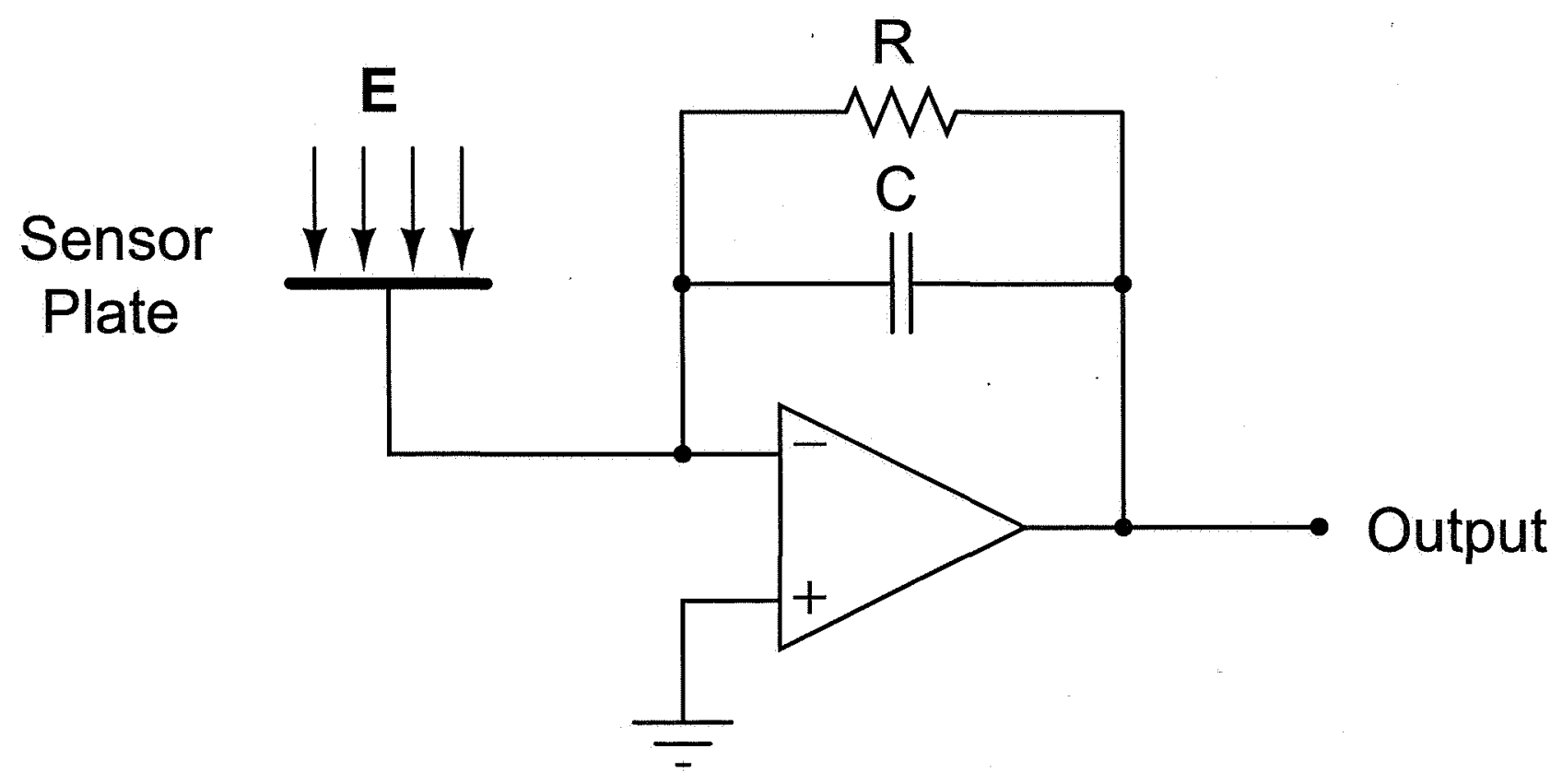

Figure 5: Shown is the schematic diagram of a charge amp. The ambient electric field, $\mathbf{E}$, induces charge $(Q)$ on the sensor plate, which is measured by the charge amp. The output voltage is given by $V_{o}=Q / C$. The feedback resistor $(R)$ slowly bleeds off charge from the capacitor, keeping the output from saturating. This also sets the low-pass cutoff frequency of the circuit at $1 / R C$. 


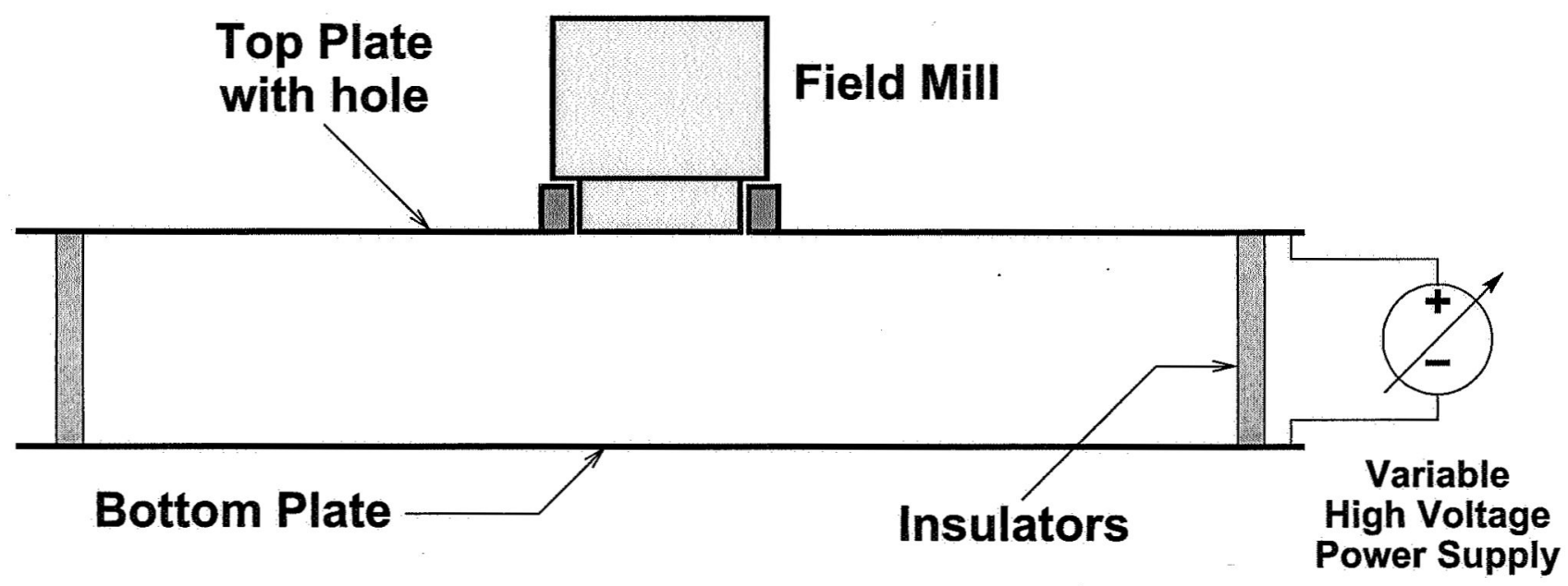

Figure 6: Shown is setup we use to calibrate electric field mills. The parallel plates are $1 \mathrm{~m}^{2}$ and the separation is $14 \mathrm{~cm}$. The field mill mounts so that the edge of the modulator is flush with the top plate, to prevent distorting the field. Various voltages in both polarities are applied to the plates, creating a variable, well-known and uniform electric field between the plates. 

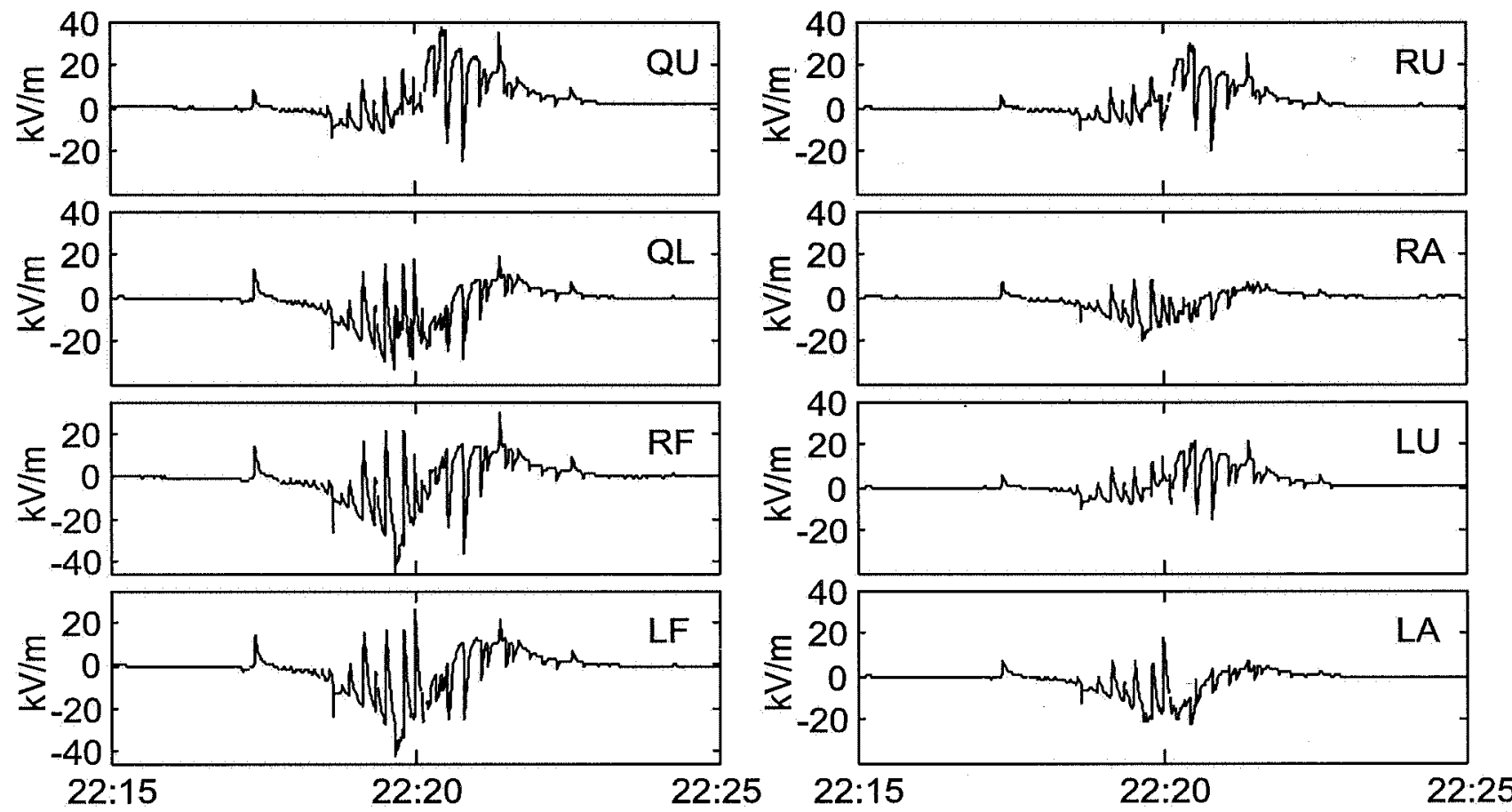

Figure 7: Data from each field mill on the ER-2 flying over a thunderstorm north of Tampa, FL on 05 Sep 1998 . The plots are labeled according to their location on the aircraft. The mills labeled QU, RU and LU point up; mills QL, RF, RA, LF and LA point down. The sharp transients are lightning flashes. 


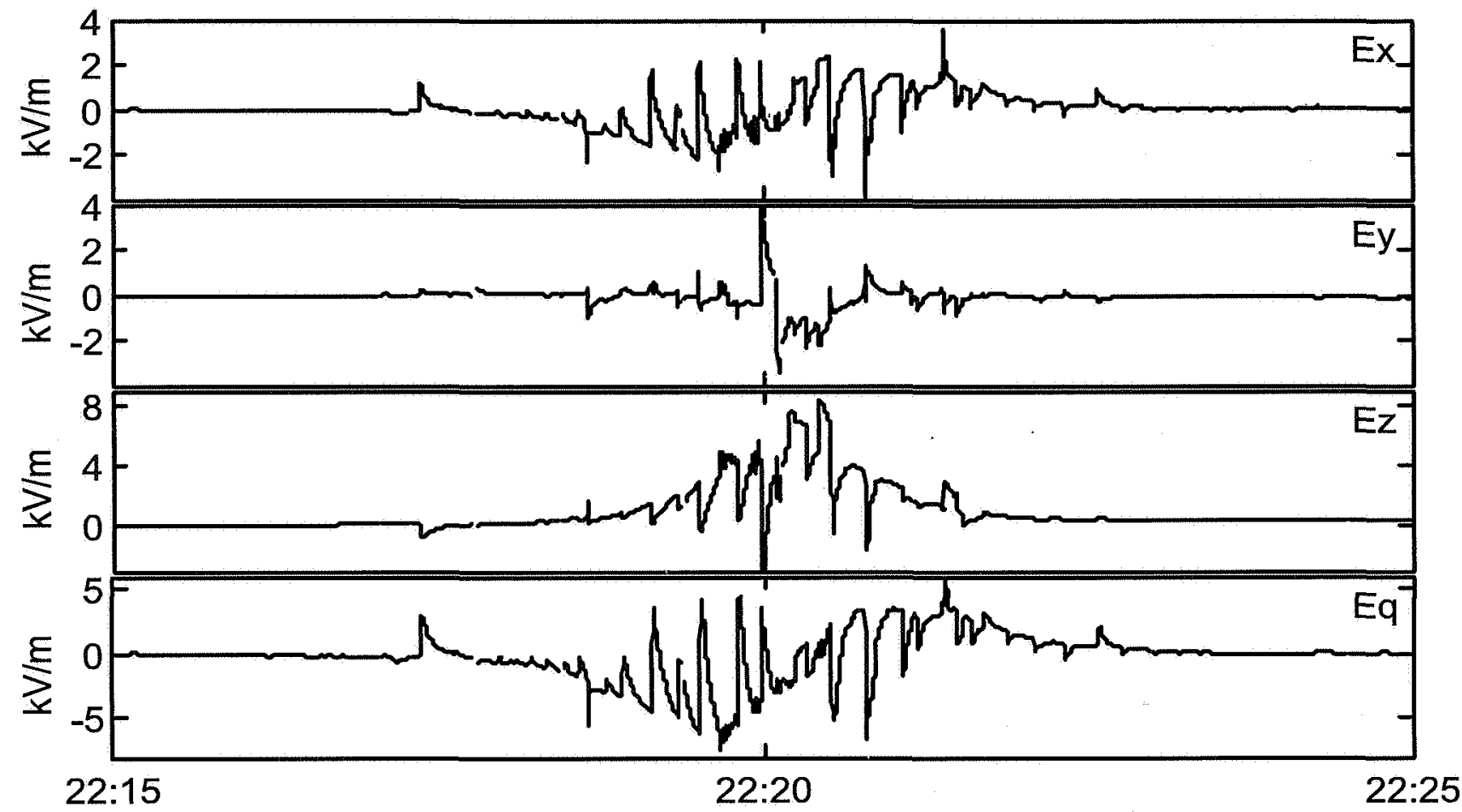

Figure 8: Electric field data from ER-2 over thunderstorm north of Tampa, FL on 05 Sep 1998. Various linear combinations of mill outputs are used with the calibration matrix; its derivation is detailed in Mach and Koshak (2003). The four (aircraft-relative) coordinates shown here are: $E_{x}$, which points in the direction of flight, positive forward; $E_{y}$, which points along the wings, positive left; $E_{z}$, which points vertically, positive up; $E_{q}$ is the field due to charge on the aircraft. The transients are field changes due to lightning. 


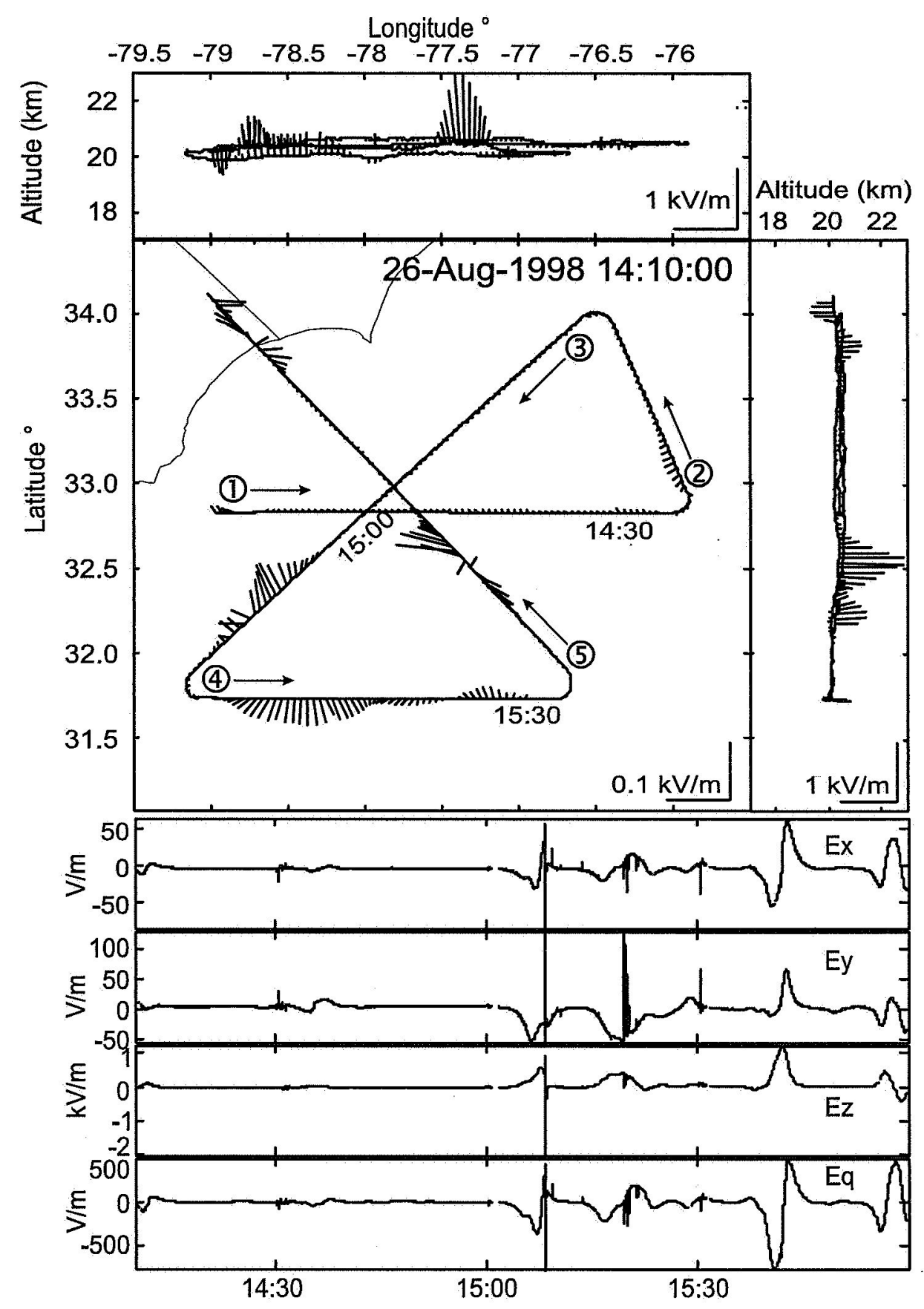

Figure 9: Electric field vectors and time series from an ER-2 flight over the eye of Hurricane Bonnie. The eye was located near $33^{\circ} \mathrm{N}, 78^{\circ} \mathrm{W}$. The upper half of the page is a 3-panel diagram, with $\mathbf{E}$ vectors superimposed on aircraft track. The top panel is an $x-z$ display showing aircraft track and electric field vectors $\left(E_{x}\right.$ and $\left.E_{z}\right)$ in that plane. The panel on the right is a $y-z$ display, again showing aircraft track and electric field vectors $\left(E_{y}\right.$ and $\left.E_{z}\right)$ in that plane. The large, center panel is an $x-y$ display showing the aircraft track and electric field vectors $\left(E_{x}\right.$ and $\left.E_{y}\right)$ in that plane. There is a scale in each panel for the vector length. Note that the $E_{z}$ field is typically an order of magnitude larger than the horizontal components, so the vectors in the $x-z$ and $y-z$ panels are scaled differently from those in the $x-y$ panel. The vector "barbs" shown are oriented so that the tail of the arrow is attached to the flight track; the electric field sign convention is that the vectors point away from positive charge. The "fan" shapes that can be seen in the $x-z$ and $y-z$ panels show that charge is below the aircraft and in the $x-y$ panel (on legs $3 \& 4$ ) to the left of the aircraft. The thin line shown in the upper left corner of the $x-y$ panel is the coastline of the Carolinas. The lower half is a time series of the field components for the same time period shown in the upper half. 


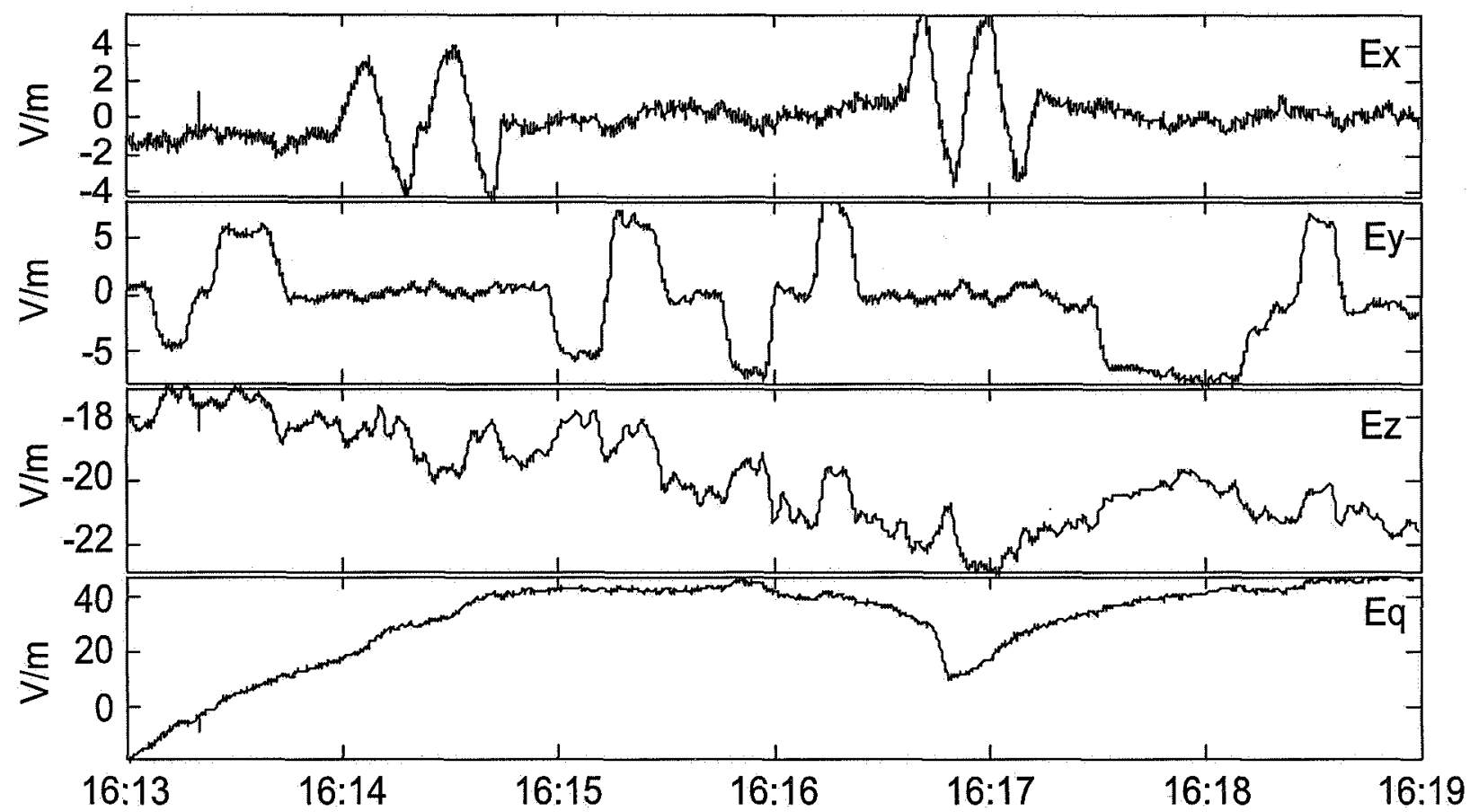

Figure 10: Electric field data from a rolls and pitches calibration maneuver. These data were collected by an Altus-II UAV in fair weather. The aircraft was flying at $3.2 \mathrm{~km}$ altitude, at which the calculated fair weather field (Gish 1944), to first order is about $-18 \mathrm{~V} / \mathrm{m}$, oriented vertically downward. Note that our measured $E_{z}$ field shows good agreement to the calculated value. Although the pitch angles are less than $10^{\circ}$ and the external field less than $20 \mathrm{~V} / \mathrm{m}$, the very low noise characteristics of the mills and aircraft allow us to clearly detect the pitch maneuvers in the field measurements (see "bumps" around 16:14 UTC and 16:17 UTC in the $E_{x}$ plot). The roll maneuvers can be clearly seen in the $E_{y}$ plot (around 16:13 and 16:15 UTC). The roll maneuvers can also be seen in the $E_{z}$ plot, as rolling the aircraft reduces the $E_{z}$ component of the field by the cosine of the roll angle (see Eqs. 1 and 2). The change in aircraft charge, $E_{q}$, just prior to 16:17 was likely caused by changing the engine RPM in preparation for the second set of pitch maneuvers. 